\title{
Procyanidin B2 Activates PPAR $y$ to Induce M2 Polarization in Mouse Macrophages
}

\author{
Ying Tian ${ }^{1}$, Chunmiao Yang ${ }^{1}$, Qinyu Yao ${ }^{1}$, Lei Qian ${ }^{2}$, Jia Liu ${ }^{1}$, Xinya Xie ${ }^{1}$, Wen Ma ${ }^{1}$, \\ Xin $\mathrm{Nie}^{2}$, Baochang Lai ${ }^{1}$, Lei Xiao ${ }^{1 *}$ and Nanping Wang ${ }^{2,3 *}$ \\ ${ }^{1}$ Cardiovascular Research Center, School of Basic Medical Sciences, Xi'an Jiaotong University, Xi'an, China, ${ }^{2}$ The Advanced \\ Institute for Medical Sciences, Dalian Medical University, Dalian, China, ${ }^{3}$ College of Basic Medical Sciences, Dalian Medical \\ University, Dalian, China
}

\section{OPEN ACCESS}

Edited by:

Dongmin Liu,

Virginia Tech, United States

Reviewed by: Anandh Babu Pon Velayutham, The University of Utah, United States

Zhenquan Jia,

University of North Carolina at

Greensboro, United States Hongwei $\mathrm{Si}$

Tennessee State University, United States

*Correspondence: Lei Xiao

xiaolei0122@xitu.edu.cn

Nanping Wang

nanpingwang2003@yahoo.com

Specialty section:

This article was submitted to Nutritional Immunology,

a section of the journal

Frontiers in Immunology

Received: 10 May 2019

Accepted: 26 July 2019

Published: 07 August 2019

Citation:

Tian Y, Yang C, Yao Q, Qian L, Liu J,

Xie X, Ma W, Nie X, Lai B, Xiao $L$ and

Wang N (2019) Procyanidin B2

Activates PPARy to Induce M2

Polarization in Mouse Macrophages.

Front. Immunol. 10:1895.

doi: 10.3389/fimmu.2019.01895
Procyanidins, a subclass of flavonoids found in commonly consumed foods, possess potential anti-inflammatory activity. Manipulation of M1/M2 macrophage homeostasis is an effective strategy for the treatment of metabolic inflammatory diseases. The objective of this study was to determine the effect of procyanidins on macrophage polarization. Procyanidin B2 (PCB2), the most widely distributed natural procyanidins, enhanced the expressions of M2 macrophage markers (Arg1, Ym1, and Fizz1). PCB2 activated peroxisome proliferator-activated receptor $\gamma$ (PPAR $\gamma$ ) activity and increased the expressions of PPAR $\gamma$ target genes (CD36 and ABCG1) in macrophages. Inhibition of PPAR $\gamma$ using siRNA or antagonist GW9662 attenuated the PCB2-induced expressions of M2 macrophage markers. In addition, we identified cognate PPAR-responsive elements (PPREs) within the 5'-flanking regions of the mouse Arg1, Ym1, and Fizz1 genes. Furthermore, macrophages isolated from $\mathrm{db} / \mathrm{db}$ diabetic mice showed lower expressions of M2 markers. PCB2 effectively restored the Arg1, Ym1, and Fizz1 expressions in a PPAR $\gamma$-dependent manner. These findings support the notion that PCB2 regulated macrophage M2 polarization via the activation of PPAR $\gamma$. Our results provide a new mechanism by which procyanidins exert their beneficial anti-inflammatory effects.

Keywords: procyanidin B2, macrophages, macrophage polarization, peroxisome proliferator-activated receptor $\gamma$, gene regulation

\section{INTRODUCTION}

Macrophages are key cellular components of innate immunity, acting as a main player in the first-line defense against pathogens and the modulation of immunological homeostasis (1). In response to various environmental signals (e.g., activated lymphocytes, damaged cells, and microbial products) or different pathophysiologic stimuli, macrophages acquire distinct functional phenotypes via undergoing different phenotypic polarization (classical M1 activation or alternative M2 activation) (2). Stimulated by lipopolysaccharides (LPS), interferon- $\gamma$ or tumor necrosis factor- $\alpha$ (TNF- $\alpha$ ), M1 macrophages are characterized by high antigen presentation and expressions of pro-inflammatory cytokines [e.g., interleukin (IL)-1 $\beta$, IL-6, and the cell membrane molecule CD86], playing an important role in host defense against infection (3). In contrast, M2 macrophages are characterized by expression of distinct marker genes such as arginase-1 (Arg1), found in inflammatory zone 1 (Fizz1), chitinase-3-like protein 3 (Ym1), and mannose receptor (CD206), exerting anti-inflammatory and tissue repairing effects (4). 
Macrophage M1/M2 polarization is a tightly controlled process involving a set of molecular signaling pathways as well as transcriptional and/or post-transcriptional regulatory networks (5). Nuclear factor-kappa B (NF-кB), signal transducer and activator of transcription 1 (STAT1), CCAAT/enhancer binding proteins $\alpha(\mathrm{C} / \mathrm{EBP}-\alpha), \mathrm{C} / \mathrm{EBP}-\delta$, interferon regulatory factor 9 (IRF9), and Krüppel-like factor 6 (KLF6) are important transcription factors involved in M1 polarization (6-9), whereas STAT3, STAT6, C/EBP- $\beta$, IRF4, KLF4, GATA binding protein 3 (GATA3), and peroxisome proliferator-activated receptors (PPARs) are associated with M2 polarization (1014). Disturbed macrophage polarization is implicated in the development of metabolic inflammatory diseases such as obesity, type 2 diabetes mellitus (T2DM) and cardiovascular diseases (15). An imbalance in the ratio of M1/M2 macrophages, with enhanced "pro-inflammatory" M1 macrophages or/and impaired "anti-inflammatory" M2 macrophages is a feature of metabolic inflammation (16). Therefore, reshaping macrophage polarization could be a potential strategy against metabolic inflammatory diseases.

Procyanidins are members of the flavonoids found in many plant foods such as apples, cocoa beans, grape seed, and red wines (17). The most common procyanidins are the B-type procyanidins (PCB) (18). Epidemiological evidence suggested that consumption of procyanidins reduced the risk of cardiovascular diseases, T2DM and cancers (19). The antiinflammatory and anti-oxidative properties might contribute to the health benefits of procyanidins (20). However, the molecular mechanisms underlying their anti-inflammatory effects remain incompletely understood. In the present study, we sought to examine whether PCB2 has an effect on macrophage polarization.

\section{MATERIALS AND METHODS}

\section{Reagents}

Procyanidin B2 (PCB2) was purchased from MedChem Express (Monmouth Junction, NJ, USA). Rosiglitazone (RGZ) and GW9662 were purchased from Sigma-Aldrich (St. Louis, MO, USA). GW6471 and GSK0660 were purchased from Cayman Chemical (Ann Arbor, Michigan, USA). Anti-CD206 and antiCD86 PE and PE-conjugated rat IgG2a, $\kappa$ were from Biolegend (San Diego, CA, USA). Rabbit polyclonal antibodies against Ym1 and Fizz1 were purchased from Abcam (Cambridge, MA, USA). Phosphorylated PPAR $\gamma$ (Ser112) rabbit polyclonal antibody was purchased from Invitrogen (Carlsbad, CA, USA). PPAR $\gamma$ antibody was from Cell Signaling Technology (Danvers, MA, USA). Antibodies against $\beta$-actin, Arg1, and horseradish peroxidase (HRP)-conjugated secondary antibodies were from Santa Cruz Biotechnology (Santa Cruz, CA, USA).

\section{Isolation of Mouse Peritoneal Cavity Macrophages (PCMs)}

We isolated PCMs from 12-week-old male C57BL/6J mice, diabetic $\mathrm{db} / \mathrm{db}$ mice on a $\mathrm{C} 57 \mathrm{BL} / \mathrm{Ks}$ J background and nondiabetic littermate $\mathrm{db} / \mathrm{m}^{+}$mice as previously described (21). Briefly, $1 \mathrm{ml}$ of $4 \%$ Brewer thioglycollate medium was injected into the peritoneal cavity. Three days later, the mice were sacrificed and peritoneal cavity was washed with ice-cold RPMI 1640 medium. The macrophages were collected from peritoneal fluid washes by refrigerated centrifuge at $400 \times \mathrm{g}$ for $10 \mathrm{~min}$. The cells were resuspended and plated for $6 \mathrm{~h}$. Attached cells were rinsed and cultured for $48 \mathrm{~h}$ before further treatment.

\section{Cell Culture and Treatment}

Mouse monocytic cell line RAW264.7 and human embryonic kidney epithelial cell line HEK293 were from American Type Culture Collection (ATCC) and cultured in Dulbecco's modified Eagle medium (DMEM, Gibco) containing 10\% fetal bovine serum (FBS, Gibco) with penicillin $(100 \mathrm{U} / \mathrm{ml})$ and streptomycin $(100 \mathrm{U} / \mathrm{ml})$ in $37^{\circ} \mathrm{C}$ with $5 \% \mathrm{CO}_{2}$. Cells were treated with indicated concentrations of PCB2 $(0.1-10 \mu \mathrm{M})$ for $24 \mathrm{~h}$ in serum-free DMEM medium. For all experiments, control cells treated with dimethylsulfoxide (DMSO, vehicle of the PCB2) were included.

\section{Quantitative Reverse Transcriptase-PCR (qRT-PCR)}

Total RNA was isolated using TRIzol (Invitrogen), converted to cDNA by using iScript cDNA synthesis kit (Bio-rad). Realtime PCR was performed by using SYBR-green dye and Taq polymerase with an ABI 7500 real-time PCR System (applied biosystems). Quantification was calculated using the comparative threshold cycle $(\mathrm{Ct})$ method and efficiency of the RT reaction (relative quantity, $2^{-\Delta \Delta \mathrm{Ct}}$ ). Primers used in qRT-PCR were shown in Supplementary Table 1.

\section{Protein Extraction and Western Blot Analysis}

Total proteins were extracted with lysis buffer $(50 \mathrm{mM}$ Tris$\mathrm{HCl}$ pH 7.4, $100 \mathrm{mM} \mathrm{NaCl}, 15 \mathrm{mM}$ EGTA, 0.1\% TritonX-100, and protease inhibitor cocktail). Nuclear proteins were isolated with high-salt buffer (20 mM Tris- $\mathrm{HCl}, 1.5 \mathrm{mM} \mathrm{MgCl}_{2}, 420 \mathrm{mM}$ $\mathrm{NaCl}, 10 \%$ glycerol, $0.2 \mathrm{mM}$ EGTA). Protein concentrations were determined with the BCA protein assay kit (Thermo Scientific). Protein samples were separated on 12\% SDS-PAGE and transferred onto polyvinylidene difluoride (PVDF) membranes. Blots were incubated with specific primary antibodies at $4^{\circ} \mathrm{C}$ overnight and HRP-conjugated secondary antibodies for $1 \mathrm{~h}$, and visualized by using the Enhanced chemiluminescence (ECL) System. $\beta$-actin was used as a loading control. Quantification of scanned images was performed with Image J software from NIH Image.

\section{Plasmids Transfection and Reporter Assay}

HEK293 cells were transfected with the plasmids expressing PPAR $\gamma$, PPRE-TK-luciferase reporter containing three copies of PPAR-response elements (PPRE) from acyl CoA oxidase (ACO) gene and $\beta$-galactosidase $(\beta$-gal) by using Lipofectamine 2000 (Invitrogen). After the treatments with PCB2 $(0.1-10 \mu \mathrm{M})$ or RGZ $(10 \mu \mathrm{M})$ for $24 \mathrm{~h}$, cell lysates were harvested to measure the luciferase and $\beta$-gal activities. Luciferase activities were normalized to $\beta$-gal activity. 


\section{Adenoviral Vectors and Infection}

For adenoviral infection, RAW264.7 cells were incubated with recombinant adenoviruses encoding PPAR $\gamma$ (Ad-PPAR $\gamma$ ) and Ad-tTA (an adenovirus expressing tTA, a tetracyclineresponsive transactivator) in the presence or absence of tetracycline $(0.1 \mu \mathrm{g} / \mathrm{ml}$, a tet-off expression) for $48 \mathrm{~h}$ as previously described (22).

\section{Flow Cytometry Analysis}

Cells were harvested and washed with cold PBS, incubated with anti-CD86 or CD206 PE, and PE-conjugated rat IgG2a, $\kappa$ served as an isotype control for $30 \mathrm{~min}$ on ice in the dark, then analyzed by flow cytometry (FACSCalibur, BD Biosciences). Data was analyzed by FlowJo software (Tree Star Inc., Ashland, OR, USA).
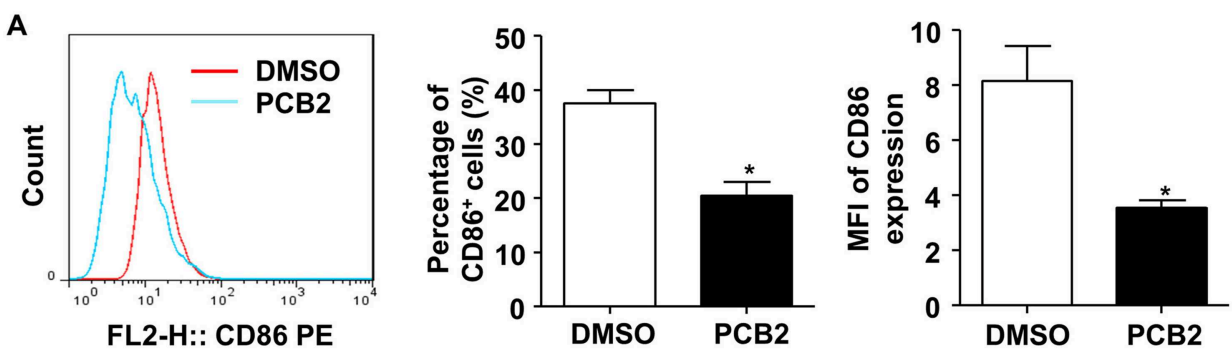

B
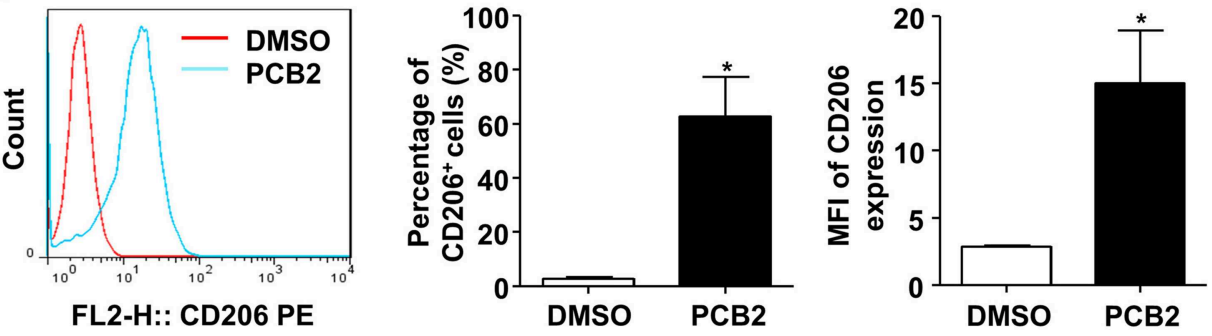

C

RAW264.7

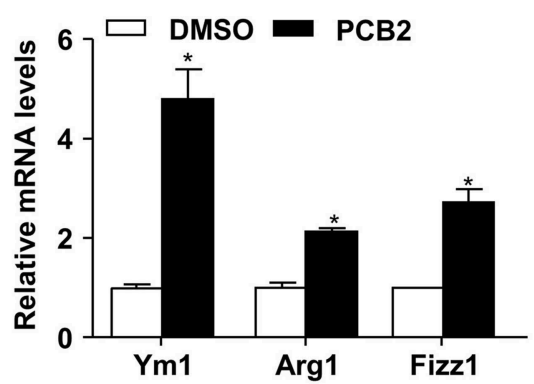

D

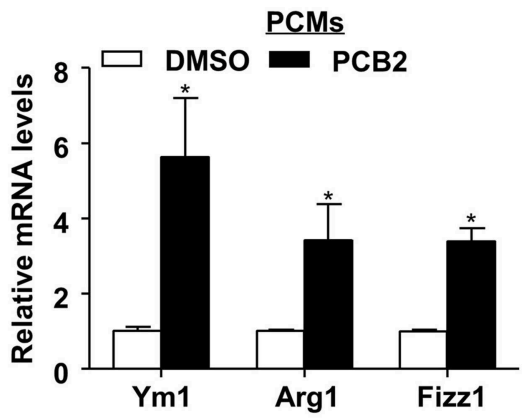

E

RAW264.7

PCMs DMSO PCB2 DMSO PCB2
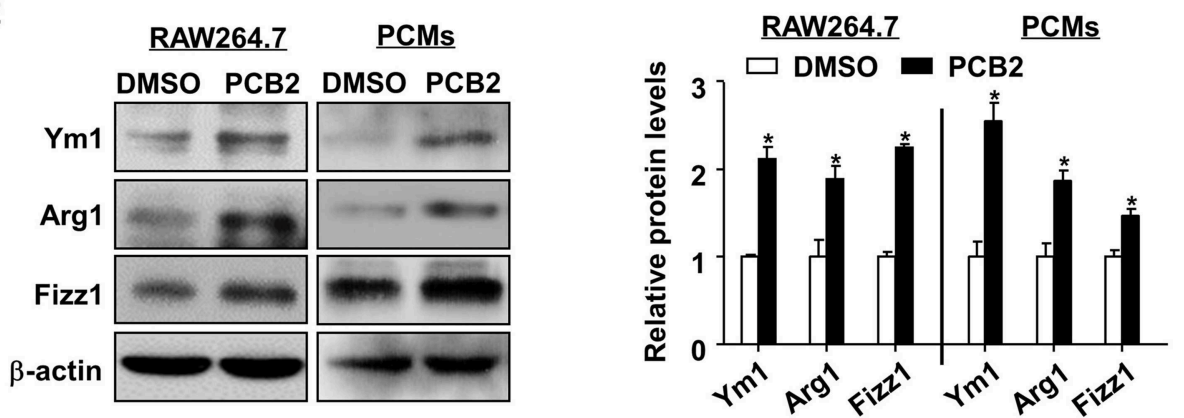

FIGURE 1 | PCB2 promoted macrophage M2 polarization. RAW264.7 cells were incubated with PCB2 $(10 \mu \mathrm{M})$ for $24 \mathrm{~h}$ and DMSO was used as vehicle control. The flow cytometry analysis was performed to evaluate the expressions of CD86 (A) and CD206 (B). Representative histograms were obtained by flow cytometry analysis. Percentage of $\mathrm{CD}^{+} 6^{+}$or $\mathrm{CD}_{206}{ }^{+}$macrophages and mean fluorescence intensity (MFI) of CD86 or CD206 expression on macrophages were quantified. RAW264.7 cells (C) and PCMs isolated from C57BL/6J mice (D) were incubated with PCB2 $(10 \mu \mathrm{M})$ for $24 \mathrm{~h}$. Total RNA was extracted and subjected to qRT-PCR for the assessment of Ym1, Arg1, and Fizz1 levels. (E) Cells lysates were analyzed for the protein levels of Ym1, Arg1, and Fizz1 by using western blotting in RAW264.7 cells and PCMs. Quantification of Ym1, Arg1, and Fizz1 protein levels. Data were shown as mean $\pm \mathrm{SEM}, n=3-6,{ }^{*} P<0.05$ vs. vehicle (DMSO). 


\section{Chromatin Immunoprecipitation (ChIP) Assay}

Cells were cross-linked with $0.75 \%$ formaldehyde, harvested, and sonicated on ice. Sheared chromatin was immunoprecipitated with anti-PPAR $\gamma$ or control IgG and protein A/G Sepharose beads. After washing, the immunoprecipitates were eluted, digested with proteinase $\mathrm{K}$ and extracted for DNA. DNA samples were amplified with primers flanking the putative PPREs in the regulatory regions of the mouse Ym1, Arg1, Fizz1 genes (the sequences are shown in Supplementary Table 2). Relative DNA binding was expressed as fold enrichment above the control IgG-immunoprecipitated samples.

\section{RNA Interference}

The siRNA sequence targeting mouse PPAR $\gamma$ was as follows: $5^{\prime}$-GGGCGAUCUUGACAGGAAATT- $3^{\prime}$ (sense) and 5'-UUUC CUGUCAAGAUCGCCCTT- $3^{\prime}$ (antisense). The siRNA with scrambled sequence was used as negative control (NC siRNA). The double-stranded RNAs $(100 \mathrm{nM})$ were transfected into RAW264.7 cells with Lipofectamine RNAi MAX (Invitrogen).

\section{Statistical Analysis}

Results are shown as the mean \pm standard error of the mean (SEM). Student's $t$ test was performed to determine statistical differences between two groups and one-way ANOVA for multiple comparisons using the SPSS 16.0 (SPSS software, IBM, USA). $P<0.05$ was considered statistically significant.

\section{RESULTS}

\section{PCB2 Promoted Macrophage M2 Polarization and Suppressed M1 Polarization}

To study the effect of PCB2 on macrophage polarization, we first evaluated the cytotoxicity of PCB2 (Figure S1A) on RAW264.7 cells and PCMs from C57BL/6J mice by using the MTT assay. Cells were treated with PCB2 at various concentrations $(0-10 \mu \mathrm{M})$ for $24 \mathrm{~h}$. As shown in Figure S1B, PCB2 caused no decrease in cell viability in both RAW264.7 and PCMs. Therefore, we used PCB2 at a concentration of $10 \mu \mathrm{M}$ to investigate the effects of PCB2 on macrophage polarization. We determined the percentage of $\mathrm{CD}^{+} 6^{+}$(a M1 marker) and $\mathrm{CD}^{206^{+}}$(a M2 marker) macrophages in the total cell population by using flow cytometry. As shown in Figures 1A,B, PCB2 diminished M1 phenotype and promoted polarization to an M2 phenotype in RAW264.7 cells. We then examined whether PCB2 increased the mRNA expression of M2 macrophage marker genes (Ym1, Arg1, and Fizz1). As shown in Figures 1C-E, PCB2 significantly increased the expressions of Ym1, Arg1, and Fizz1 both on mRNA and protein levels in RAW264.7 cells as well as in PCMs. Further, we treated RAW264.7 cells with PCB2 before the exposure to LPS and found that PCB2 inhibited LPS-stimulated expression of IL-6 and TNF- $\alpha$, the M1 marker genes (Figure S2). Taken together, these results indicated that PCB2 promoted M2 macrophages polarization.

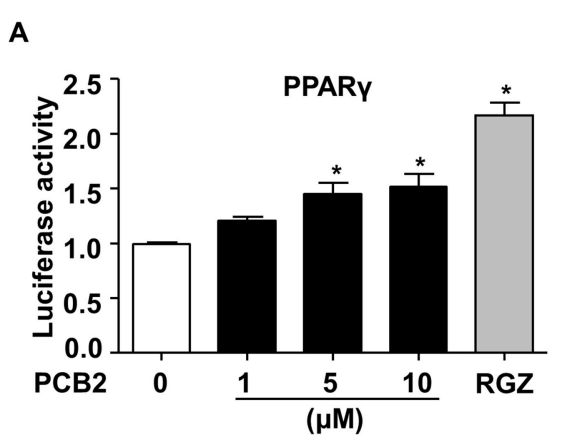

B

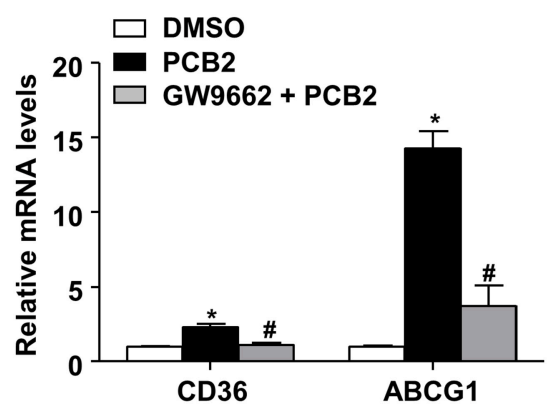

C

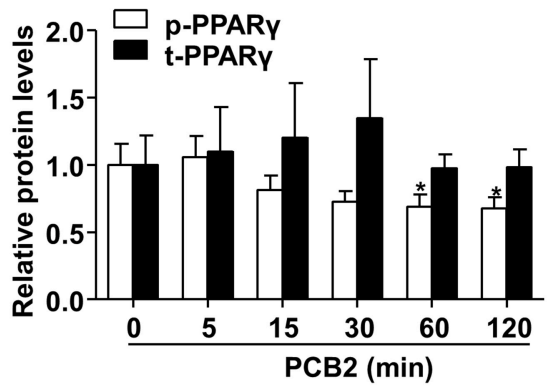

FIGURE 2 | PCB2 activated PPAR $\gamma$ in RAW264.7 cells. (A) HEK293 cells were transfected with PPRE-luc and PPAR $\gamma$ plasmids and then treated with PCB2 $(0-10 \mu \mathrm{M})$ or RGZ $(10 \mu \mathrm{M}$, positive control) for $24 \mathrm{~h}$. The luciferase activities were expressed as fold changes $(n=3)$. (B) RAW264.7 cells were pre-treated with GW9662 $(5 \mu \mathrm{M})$ for $1 \mathrm{~h}$, then exposed to PCB2 $(10 \mu \mathrm{M})$ for $24 \mathrm{~h}$, mRNA levels of CD36 and ABCG1 were measured by qRT-PCR $(n=4-6)$. (C) RAW264.7 cells were treated with PCB2 $(10 \mu \mathrm{M})$ for 0-120 min, then nuclear extracts were analyzed for total and phosphorylated-PPAR levels by using western blotting. Quantification of p-PPAR $\gamma$ and t-PPAR $\gamma$ levels in RAW264.7 cells $(n=6)$. Data were shown as mean \pm SEM, ${ }^{*} P<0.05$ vs. vehicle; $\# P<0.05$ vs. PCB2. 


\section{PCB2 Activated PPAR $\gamma$}

Activation of PPAR $\gamma$ potentiated the polarization of circulating monocytes to macrophages of the M2 phenotype (23). Thus, we examined whether PCB2 activated PPAR $\gamma$ activity. HEK293 cells were transfected with PPAR $\gamma$ expression and the PPRE-driven luciferase reporter plasmids before the exposure to PCB2. The reporter assay showed that $\mathrm{PCB} 2$ increased the PPAR $\gamma$ activity (Figure 2A). Further, we examined the effects of PCB2 on the expressions of the endogenous PPAR $\gamma$ target genes, such as cluster of differentiation 36 (CD36) and ATP binding cassette
A

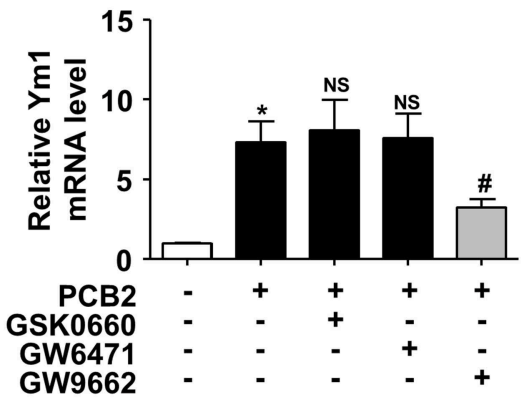

4

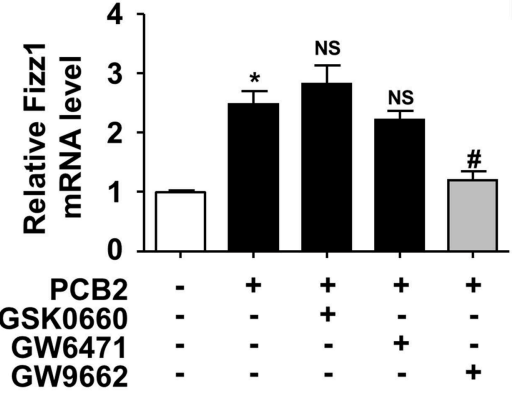

C

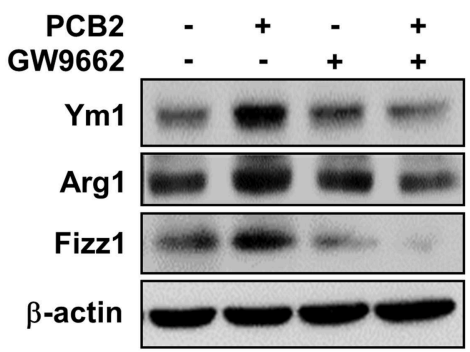

D

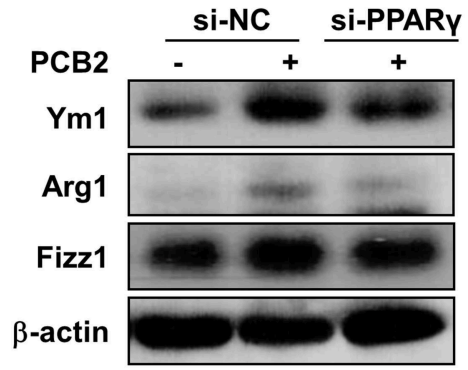

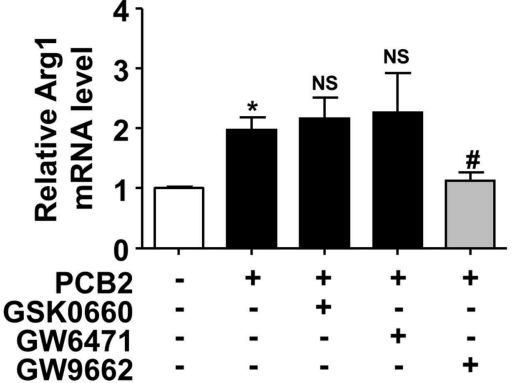

B
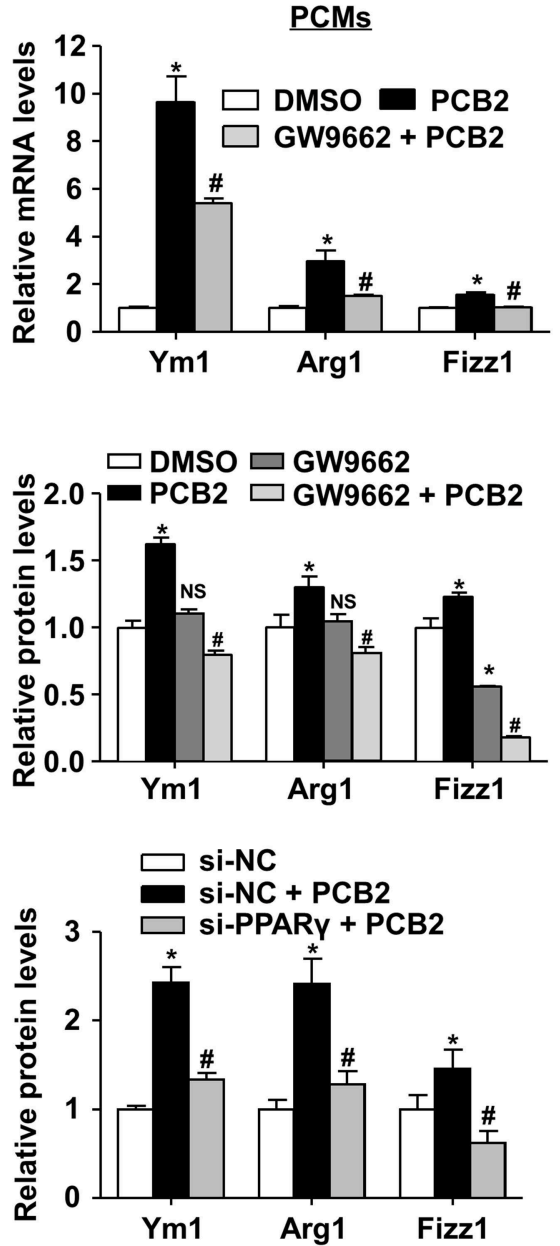

FIGURE 3 | PCB2 promoted macrophage M2 polarization via PPAR $\gamma$ activation. (A) RAW264.7 cells were pre-treated with GSK0660 (2 $\mu \mathrm{M})$, GW6471 (2 $\mu \mathrm{M})$, or GW9662 $(5 \mu \mathrm{M})$ for $1 \mathrm{~h}$, then exposed to PCB2 $(10 \mu \mathrm{M})$ for $24 \mathrm{~h}$. Total RNA was extracted and subjected to qRT-PCR for the assessments of Ym1, Arg1, and Fizz1 mRNA levels. (B) PCMs were pre-treated with GW9662 $(5 \mu \mathrm{M})$ for $1 \mathrm{~h}$, then exposed to PCB2 (10 $\mu \mathrm{M})$ for $24 \mathrm{~h}$. Expression of Ym1, Arg1, and Fizz1 were measured by qRT-PCR. (C) Ym1, Arg1, and Fizz1 protein levels were measured by using western blotting. (D) RAW264.7 cells were transfected with PPARy siRNA or NC siRNA for $24 \mathrm{~h}$ and then treated with PCB2 $(10 \mu \mathrm{M})$ for another $24 \mathrm{~h}$. Ym1, Arg1, and Fizz1 protein levels were detected by using western blotting. Data were shown as mean \pm SEM, $n=3-5,{ }^{*} P<0.05$ vs. control; $\# P<0.05$ vs. PCB2 or NC siRNA treated with PCB2; NS, not significant. 
subfamily G member 1 (ABCG1) in RAW264.7 cells. As shown in Figure 2B, mRNA levels of CD36 and ABCG1 were increased by PCB2. However, GW9662, a selective antagonist of PPAR $\gamma$, effectively abrogated the induction of CD36 and ABCG1 by PCB2, suggesting a PPAR $\gamma$-specific mechanism.

Phosphorylation-mediated inhibition of transcriptional activity of nuclear receptors is an important "off-switch" of ligand-induced activity (24). It has been reported that phosphorylation of PPAR $\gamma$ by mitogen-activated protein kinase (MAPK) at serine 112 decreased ligand-binding affinity and affected coactivator recruitment (25). Thus, we investigated whether PCB2 inhibited the serine 112 phosphorylation of PPAR $\gamma$ to increase its activity in RAW264.7 cells. As shown in Figure 2C, PCB2 significantly decreased PPAR $\gamma$ phosphorylation with little effect on total protein level of PPAR $\gamma$ within the observed time periods. Taken together, we demonstrated that

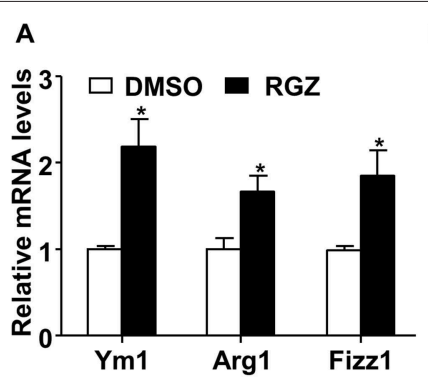

B
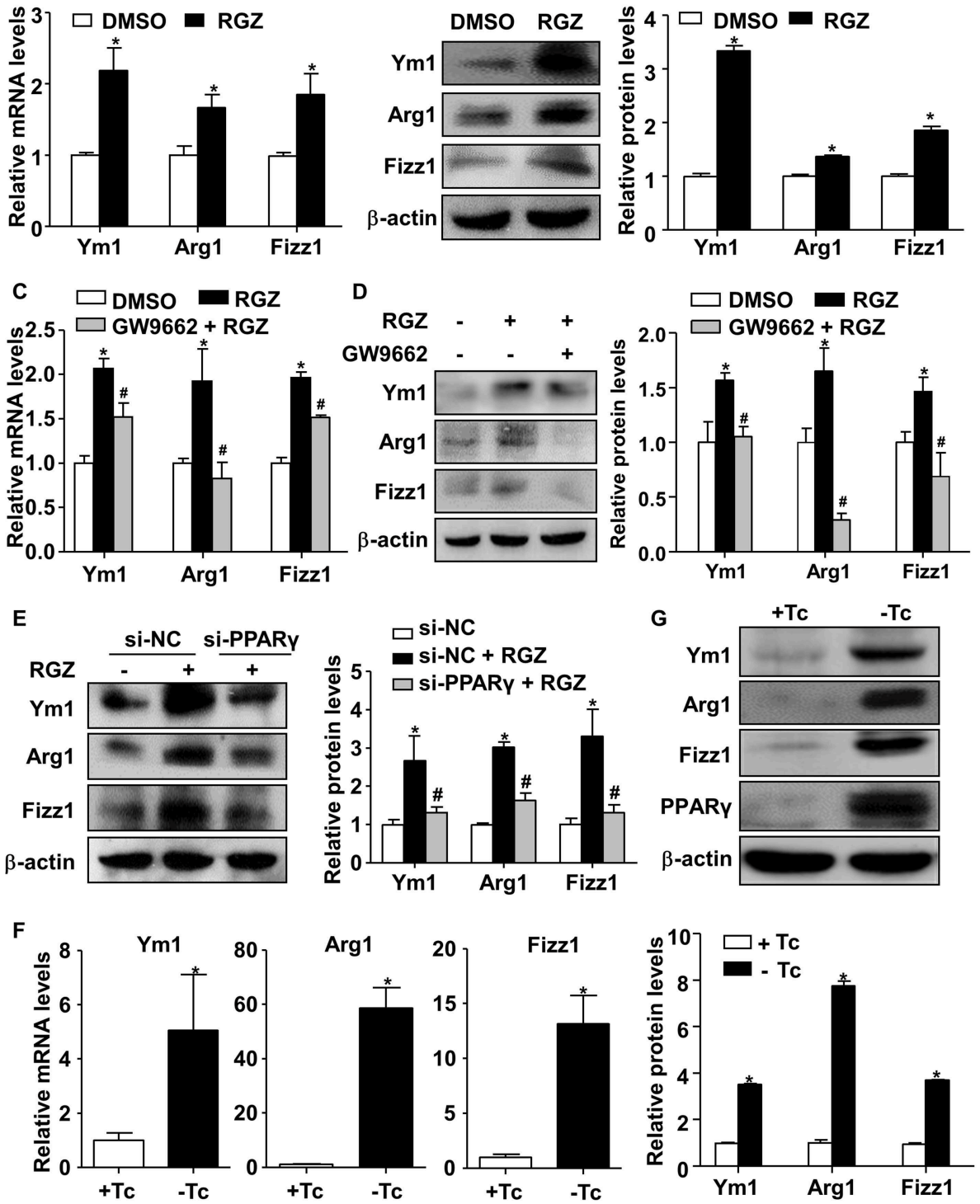

FIGURE 4 | PPAR $\gamma$ transactivated Ym1, Arg1, and Fizz1 in RAW264.7 cells. (A) RAW264.7 cells were treated with RGZ (10 $\mu$ M) for $24 \mathrm{~h}$ and DMSO as vehicle control. Total RNA was extracted and subjected to qRT-PCR for the assessment of Ym1, Arg1, and Fizz1 mRNA levels. (B) Ym1, Arg1, and Fizz1 protein levels were measured by using western blotting. (C) RAW264.7 cells were pre-treated with GW9662 (5 $\mu \mathrm{M})$ for $1 \mathrm{~h}$, then exposed to RGZ (10 $\mu \mathrm{M})$ for $24 \mathrm{~h}$. The mRNA levels of Ym1, Arg1, and Fizz1 were assessed by qRT-PCR. (D) The protein levels of Ym1, Arg1, and Fizz1 were measured by western blotting. (E) RAW264.7 cells were transfected with PPAR $\gamma$ siRNA or NC siRNA for $24 \mathrm{~h}$, and then exposed to RGZ $(10 \mu \mathrm{M})$ for $24 \mathrm{~h}$. Protein levels of Ym1, Arg1, and Fizz1 were detected by using western blotting. (F) RAW264.7 cells were infected with Ad-PPARy and Ad-tTA with or without Tc ( $0.1 \mu \mathrm{g} / \mathrm{ml})$ for $48 \mathrm{~h}$. The mRNA levels of Ym1, Arg1, and Fizz1 were assessed by qRT-PCR. (G) The protein levels of PPAR $\gamma$, Ym1, Arg1, and Fizz1 were measured by western blotting. Data were shown as mean \pm SEM, $n=3-4,{ }^{*} P<$ 0.05 vs. control; $\# P<0.05$ vs. RGZ or NC siRNA treated with RGZ. 
PCB2 inhibited PPAR $\gamma$ phosphorylation and activated PPAR $\gamma$ in macrophages.

\section{PCB2 Promoted Macrophage M2 Polarization via PPAR $\gamma$ Activation}

To study whether PPAR $\gamma$ activity was required for the macrophage M2 polarization induced by PCB2, we pre-treated RAW264.7 cells with GW6471 (a selective PPAR $\alpha$ antagonist), GSK0660 (a selective PPAR $\delta$ antagonist), or GW9662 (a selective PPAR $\gamma$ antagonist) before the exposure to PCB2. As shown in Figure 3A, GW9662, but not GSK0660 or GW6471, significantly attenuated the effects of PCB2 on Ym1, Arg1, and Fizz1 mRNA levels. Experiments conducted in mouse PCMs also confirmed that PCB2 induction of Ym1, Arg1, and Fizz1 levels was attenuated by GW9662 (Figure 3B). GW9662 also abolished the PCB2 increased Ym1, Arg1, and Fizz1 at protein levels in RAW264.7 cells (Figure 3C). We also used the siRNA to silence the expression of endogenous PPAR $\gamma$. As shown in Figure 3D, knockdown of PPAR $\gamma$ effectively diminished the induction of Ym1, Arg1, and Fizz1 by PCB2. Taken together, these results demonstrated that PCB2 promoted macrophages M2 polarization via a PPAR $\gamma$-dependent manner.

\section{PPAR $\gamma$ Transcriptionally Activated Ym1, Arg1, and Fizz1 in RAW264.7 Cells}

To further examine how PCB2 induced the expressions of Ym1, Arg1, and Fizz1 via PPAR $\gamma$, RAW264.7 cells were treated with RGZ, a specific agonist of PPAR $\gamma$, for $24 \mathrm{~h}$. As shown in Figures 4A,B, RGZ effectively induced Ym1, Arg1, and Fizzl expressions at both mRNA and protein levels. To ascertain that RGZ acts via PPAR $\gamma$, we treated RAW264.7 cells with GW9662 before the exposure to RGZ. As shown in Figures 4C,D, the RGZ increased Ym1, Arg1, and Fizz1 levels were significantly abrogated by GW9662. Knockdown

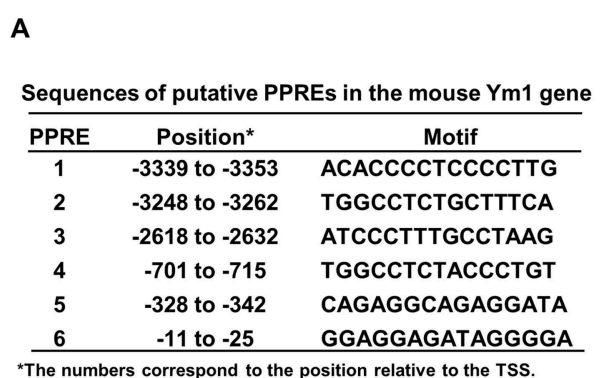

C

Sequences of putative PPREs in the mouse Fizz1 gene

\begin{tabular}{ccc}
\hline PPRE & Position $^{*}$ & \multicolumn{1}{c}{ Motif } \\
\hline 1 & -1675 to -1689 & TCAACTTTCCCCTCT \\
2 & -1149 to -1163 & TGACCTTTAGCACAA \\
3 & -845 to -859 & TAAACTTTGTTCTAA \\
4 & +180 to +194 & TGTCCTTTCCCTCAC \\
\hline
\end{tabular}

*The numbers correspond to the position relative to the TSS.

E

\begin{tabular}{|c|c|c|}
\hline PPRE & Position* & Motif \\
\hline 1 & -1807 to -1821 & TGACCTTTGAACTAA \\
\hline 2 & -990 to -1004 & GGAGGTCAGAGATCA \\
\hline 3 & -888 to -920 & TСTСАTСTGCССTAG \\
\hline 4 & -803 to -817 & TGCCCATTGCTCCGT \\
\hline 5 & -250 to -264 & AGCACCCTGCCCTGA \\
\hline 6 & +11 to +25 & TGCCСTсTGTCTTTT \\
\hline
\end{tabular}
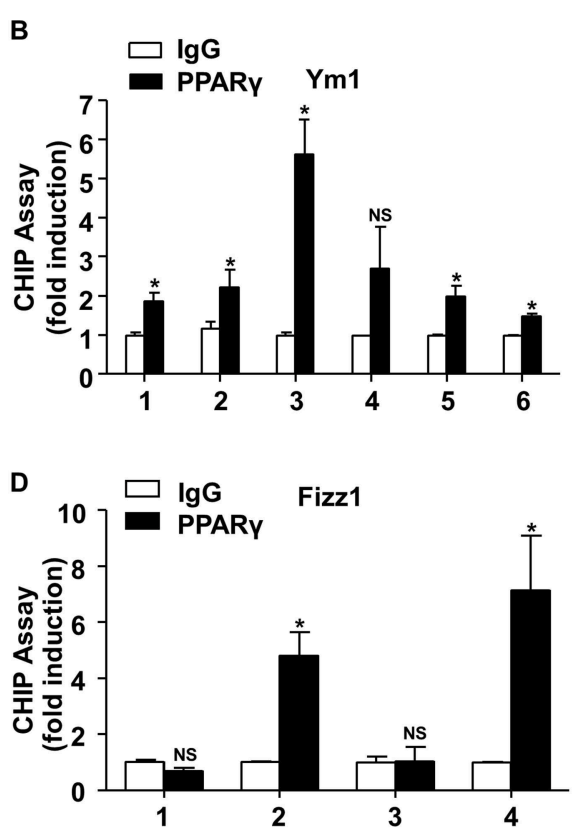

$\mathbf{F}$

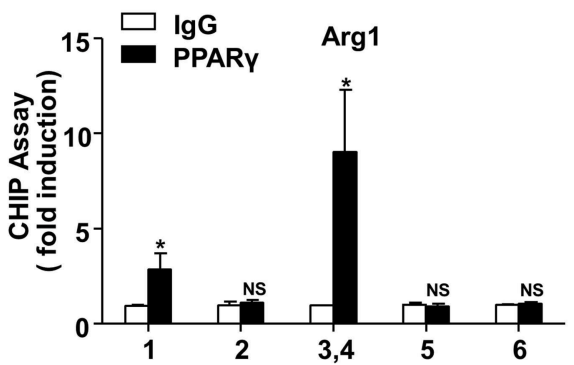

FIGURE 5 | Identification of PPAR $\gamma$-binding sites in the mouse Ym1, Arg1, and Fizz1 promoters. (A,C,E) Putative PPREs in the mouse Ym1, Fizz1, Arg1 gene promoters are listed with their positions in relation to TSS and core sequences. (B,D,F) ChIP assays were performed in RAW264.7 cells overexpressing PPARy with the use of anti-PPAR $y$ antibody or IgG as control. PPRE binding was quantified by using qPCR with the primers flanking the putative PPREs in the Ym1 (B), Fizz1 (D), Arg1 (F) gene promoters. The PCR results were expressed as fold change compared with IgG control. Data were shown as mean $\pm \mathrm{SEM}, n=3-8,{ }^{\star} P<0.05 \mathrm{vs}$. IgG control; NS, not significant. 
of PPAR $\gamma$ also effectively diminished the induction of Ym1, Arg1, and Fizz1 by RGZ (Figure 4E). To further confirm the effects of PPAR $\gamma$ on Ym1, Arg1, and Fizz1 expressions, we adenovirally overexpressed PPAR $\gamma$ in RAW264.7 cells. As shown in Figures 4F,G, overexpression of PPAR $\gamma$ increased the expressions of Ym1, Arg1, and Fizz1 genes at both mRNA and protein levels.

\section{Identification of PPAR $\gamma$-Binding Sites in the Ym1, Arg1, and Fizz1 Gene Promoters}

Next, we examined the mechanism by which PPAR $\gamma$ increased Ym1, Arg1, and Fizz1 expressions. Sequences analysis of the 5 -flanking regions of mouse Ym1, Fizz1, Arg1 genes by using our previously established prediction tool (http://www.ppargene. org) (26) and the online database of transcription factor binding profiles (http://jaspar.genereg.net) revealed multiple putative PPREs within the 4,000-bp regions upstream of the transcription start sites (TSS) (Figures 5A,C,E). ChIP assays showed that PPAR $\gamma$ could directly bind to the PPREs located at -3353/-3339 (PPRE1), -3262/-3248 (PPRE2), -2632/-2618 (PPRE3), $-342 /-328$ (PPRE5), and $-25 /-11$ (PPRE6) in the flanking region of the mouse $\mathrm{Ym} 1$ gene (Figure 5B), at $-1163 /-1149$ (PPRE2), +180/+194 (PPRE4) in the mouse Fizz1 gene (Figure 5D), and at $-1821 /-1807$ (PPRE1), -920/-888 (PPRE3), -817/-803 (PPRE4) in the mouse Arg1 gene
(Figure 5F). These results indicated that Ym1, Arg1, and Fizz1 were direct targets of PPAR $\gamma$ in mouse macrophages.

\section{PPAR $\gamma$ Was Required for PCB2-Enhanced M2 Polarization in Diabetic Mice}

Macrophages infiltration in vessel walls and adipose tissues is a pathological feature in atherosclerosis and obesity (27). To investigate whether PCB2 altered macrophage polarization in obese diabetic mice, we isolated PCMs from $\mathrm{db} / \mathrm{db}$ mice and treated them with PCB2 for $24 \mathrm{~h}$. As shown in Figure 6 , compared with $\mathrm{db} / \mathrm{m}^{+}$control mice, M2 markers (Ym1, Arg1, and Fizz1) were down-regulated in PCMs from $\mathrm{db} / \mathrm{db}$ mice. PCB2 significantly restored the downregulated M2 markers in $\mathrm{db} / \mathrm{db}$ PCMs. However, the reversal of macrophage M2 polarization markers was abolished when the cells were preincubated with PPAR $\gamma$ antagonist GW9662.

\section{DISCUSSION}

In this study, we demonstrated that PCB2, a natural flavonoid, induced M2 macrophage polarization via the activation of PPAR $\gamma$. This was supported by several lines of evidence: (1) PCB2 decreased the number of M1 macrophages and enhanced the expressions of M2 markers; (2) PCB2 activated PPAR $\gamma$; (3) Both genetic and pharmacological inhibitions of PPAR $\gamma$ abrogated
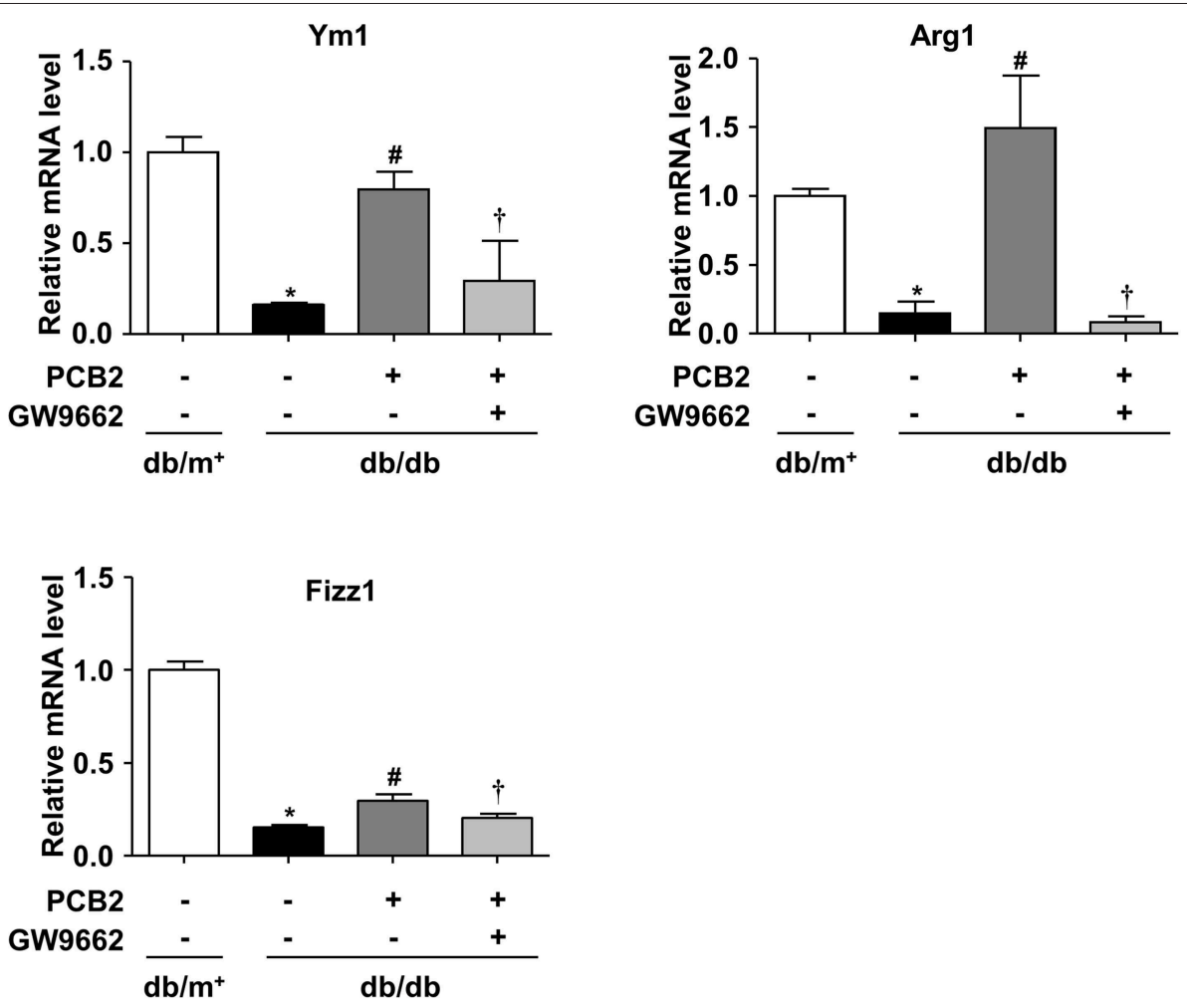

FIGURE 6 | PCB2 ameliorated impaired M2 polarization via PPAR $\gamma$ activation. PCMs isolated from $\mathrm{db} / \mathrm{db}$ or $\mathrm{db} / \mathrm{m}^{+}$mice were pre-treated with or without GW9662 $(5 \mu \mathrm{M})$ for $1 \mathrm{~h}$, then exposed to PCB2 $(10 \mu \mathrm{M})$ for $24 \mathrm{~h}$. The mRNA levels of Ym1, Arg1, and Fizz1 were measured by qRT-PCR. Data were shown as mean \pm SEM, $n=6,{ }^{*} P<0.05 \mathrm{vs} . \mathrm{db} / \mathrm{m}^{+}$treated with vehicle; $\# P<0.05 \mathrm{vs}$. db/db treated with vehicle; ${ }^{\dagger} P<0.05 \mathrm{vs} . \mathrm{db} / \mathrm{db}$ treated with $P C B 2$. 
expressions of M2 markers induced by PCB2; (4) PPAR $\gamma$ transcriptionally activated Arg1, Ym1, and Fizz1 in macrophages;

(5) PPAR $\gamma$ activation was required for PCB2 amelioration of the impaired M2 polarization in diabetic mice.

Procyanidins present in many plant foods, such as cinnamon, grape, cocoa beans, and apples (17). Fruit consumption has been associated with a reduced risk for cardiovascular disease both in Western and Chinese populations $(28,29)$. The protective effect was generally attributed, at least in part, to the anti-inflammatory activity of procyanidins in fruits. Our previous study showed that PCB2 inhibited the activation of NLRP3 inflammasome via the suppression of AP-1 pathway in endothelial cells (18). Terra et al. showed that procyanidins inhibited pro-inflammatory molecules C-reactive protein (CRP) and IL-6 expression whereas enhanced the expression of anti-inflammatory molecules, decreasing the low-grade metabolic inflammation in vivo (30). Byun et al. found that procyanidin C1 inhibited LPS-induced MAPK and NF- $\kappa$ B activations through toll-like receptor 4 (TLR4) in RAW264.7 cells and primary bone marrow-derived macrophages (BMDMs) (31). In the present study, we found that PCB2 suppressed pro-inflammatory macrophage M1 polarization and enhanced macrophage M2 polarization (Figure 1). The physiological concentrations of PCB2 are highly variable and depend on the dietary conditions and the techniques of detection (32-34). In human, plasma level of PCB2 reached $41 \pm 4 \mathrm{nM}$ at $2 \mathrm{~h}$ after the consumption of cocoa (35). Shoji et al. intragastrically administrated apple procyanidins to Wista rats and used HPLCtandem MS to detect a plasma level of PCB2 as $17.6 \pm 3.8 \mu \mathrm{M}$ (36). In previous studies, PCB2 were used at $20-200 \mu \mathrm{M}$ in U937, THP-1, RAW264.7, and HL-60 cell lines (37-40). Here, we used PCB2 at $10 \mu \mathrm{M}$, which is much higher than the plasma level in human after usual food intake but is achievable in animals.

Peroxisome proliferator-activated receptor $\gamma(\operatorname{PPAR} \gamma)$ is one of a family of nuclear receptors that is responsible for regulating glucose homeostasis, cell differentiation, lipid metabolism, and

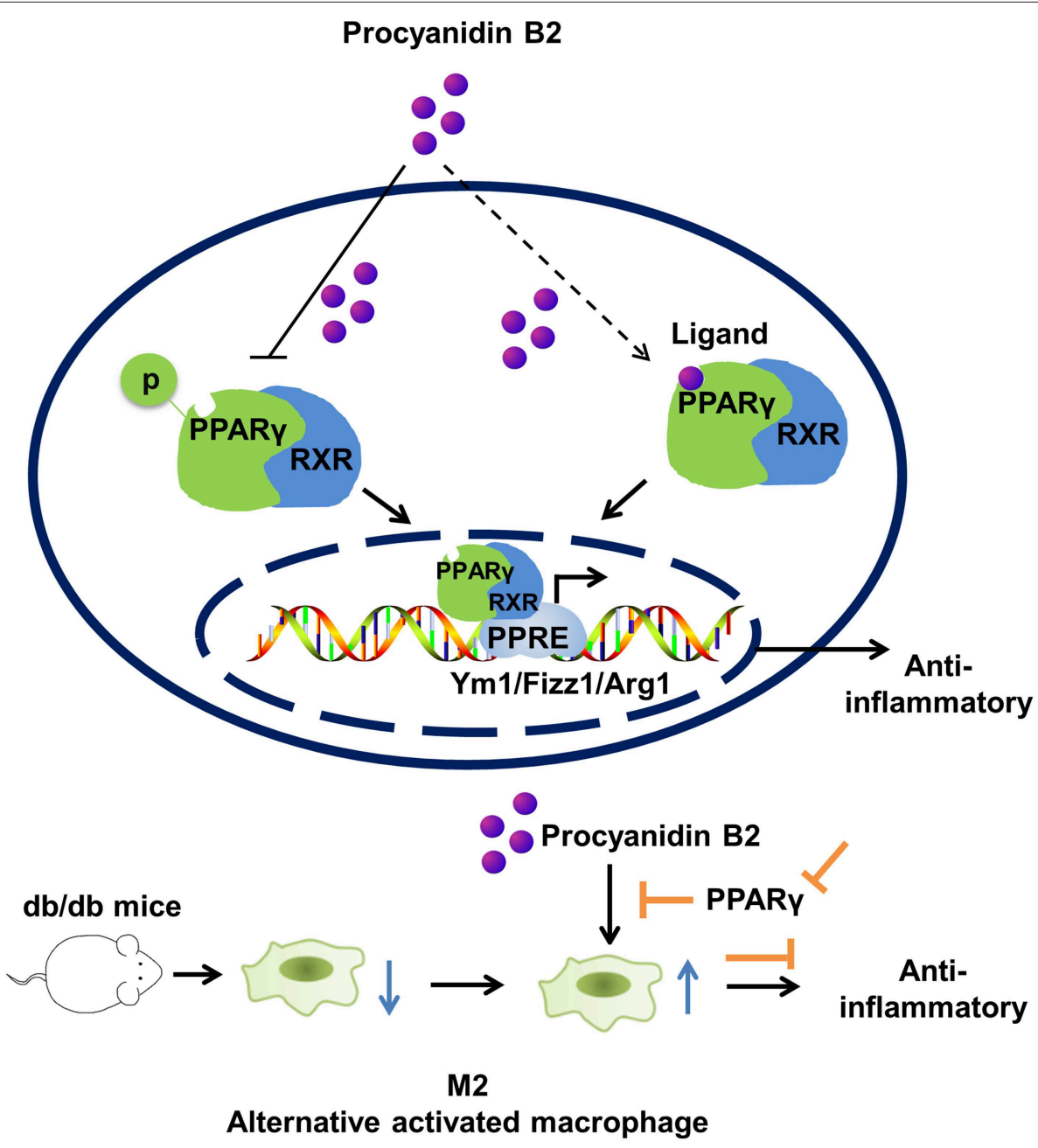

FIGURE 7 | Effect of PCB2 on macrophage polarization. PCB2 enhanced the expressions of M2 markers (Arg1, Ym1, and Fizz1) and activated PPAR $\gamma$ activity in macrophages. Compared with $\mathrm{db} / \mathrm{m}^{+}$control mice, macrophages isolated from db/db diabetic mice showed an impaired M2 phenotype. PCB2 effectively restored the M2 polarization in a PPAR $\gamma$-dependent manner. 
inflammation (41). In addition, PPAR $\gamma$ activation is involved in M2 polarization (23). We attempted to determine whether PCB2 could exert anti-inflammatory through PPAR $\gamma$ activation. Here, we showed that PCB2 promoted M2 macrophage polarization mainly depending on PPAR $\gamma$. This notion was supported by its capacity of activating the PPAR $\gamma$-reporter and the induction of endogenous PPAR $\gamma$ target genes. More importantly, the effects of PCB2 on the induction of target genes and M2 markers were attenuated by PPAR $\gamma$ inhibition (Figure 2). PPAR $\gamma$ could be phosphorylated by MAPK, AMP-activated protein kinase (AMPK) or protein kinase C (PKC) $(42,43)$. In this study, we showed that PCB2 blocked PPAR $\gamma$ serine 112 phosphorylation, which might be one putative mechanism for the regulation of PPAR $\gamma$ activity by PCB2 (Figure 3). However, it remains to be examined whether this phytochemical serves as a bona fide ligand for $\operatorname{PPAR} \gamma$. PPAR $\gamma$ agonists are used to treat insulin resistance associated with metabolic syndrome and T2DM (44). By using AutoDock, a tool for virtual screening of molecular interactions, we found that PCB2 has a potential binding with PPAR $\gamma$ (data not shown).

In the present study, we also provided evidence that PPAR $\gamma$ activation is necessary for PCB2 induction of M2 polarization. PPAR $\gamma$ agonist and Ad-PPAR $\gamma$ increased the induction of Arg1, Ym1, and Fizzl at both mRNA and protein levels. The induced expressions of Arg1, Ym1, and Fizz1 by PPAR $\gamma$ agonist were attenuated by inhibition of PPAR $\gamma$ (Figure 4). Furthermore, we identified Arg1, Ym1, and Fizzl as direct targets of PPAR $\gamma$ (Figure 5). As a transcription factor, the primary mechanism for $\operatorname{PPAR} \gamma$ to regulate gene expression is through its binding to specific PPRE in the regulatory regions of the target genes. In the present study, we found recurrent PPREs in the mouse Arg1, Ym1, and Fizz1 promoters and confirmed the PPAR $\gamma$ binding. Indeed, a previous study showed that Arg1 was regulated by PPAR $\gamma$ and involved in M2 polarization (23).

Chronic inflammation is an important pathological feature of obesity, T2DM as well as cardiovascular diseases (45). Resolving metabolic inflammation is one potential strategy to treat these metabolic disorders (46). Metformin (47) and thiazolidinediones (23) have been known to restrain low-grade inflammation. On the other hand, searching natural compounds modulating inflammation represents a promising approach for the treatment. Recently, several natural agents, such as lupeol (48), resveratrol (49), and geraniin (50), were reported to modulate macrophage polarization in several pathologic contexts. In the present study, expression of Arg1, Ym1, and Fizzl was markedly decreased in PCMs isolated from diabetic $\mathrm{db} / \mathrm{db}$ mice. Impaired expressions of M2 markers were significantly reversed by PCB2 treatment. However, GW9662 attenuated the effect of PCB2 in $\mathrm{db} / \mathrm{db}$ PCMs (Figure 6). In various rodent models for diabetes, anti-diabetic effects of procyanidins have been reported, including their roles in insulin secretion and sensitivity, food intake, obesity, and inflammatory and oxidative responses (51). Previously, we reported that PCB2 attenuated NLRP3 inflammasome activation in endothelial cells (18). Since NLRP3 inflammasome activation and endothelial dysfunction are also important pathophysiological steps in diabetes and cardiovascular diseases, PCB2 may exert pleiotropic effects in vivo. Nevertheless, our in vitro and ex vivo findings demonstrated a macrophage-specific nutritional immunology action of procyanidins. However, it is worth noting that procyanidins can be converted into multiple metabolites through metabolism in vivo (52). Further study of the pharmacodynamics and kinetics of PCB2 may help understanding of the therapeutic actions and the pharmacological modes of PCB2 in the prevention and treatment of metabolic disorders.

\section{CONCLUSION}

Our findings demonstrated that PCB2 regulated macrophage M2 polarization in mouse macrophages via the activation of PPAR $\gamma$ (Figure 7). More importantly, our results demonstrated that PCB2 ameliorated obesity-related inflammation via a PPAR $\gamma$-dependent up-regulation of Ym1, Arg1, and Fizz1. This finding revealed a novel mechanism underlying the beneficial effects of dietary procyanidins on metabolic and inflammatory diseases.

\section{DATA AVAILABILITY}

The datasets generated for this study are available on request to the corresponding author.

\section{ETHICS STATEMENT}

Animal care and experimental protocols were in accordance with the National Institutes of Health (NIH) Guide for the Care and Use of Laboratory Animals with the approval by the Animal Research Committee of Xi'an Jiaotong University.

\section{AUTHOR CONTRIBUTIONS}

LX and NW conceived the study, analyzed the data, and wrote the manuscript. YT performed most of the experiments and wrote the manuscript. CY, WM, XX, QY, LQ, JL, XN, and BL performed experiments and provided technical support. All authors had read and approved the manuscript.

\section{FUNDING}

This study was supported by grants from the National Key R\&D Program of China (2018YFA0800600) and National Science Foundation of China (31430045, 81830015, and 81770497).

\section{SUPPLEMENTARY MATERIAL}

The Supplementary Material for this article can be found online at: https://www.frontiersin.org/articles/10.3389/fimmu. 2019.01895/full\#supplementary-material 


\section{REFERENCES}

1. Arango Duque G, Descoteaux A. Macrophage cytokines: involvement in immunity and infectious diseases. Front Immunol. (2014) 5:491. doi: 10.3389/fimmu.2014.00491

2. Mantovani A, Biswas SK, Galdiero MR, Sica A, Locati M. Macrophage plasticity and polarization in tissue repair and remodelling. J Pathol. (2013) 229:176-85. doi: 10.1002/path.4133

3. Martinez FO, Gordon S. The M1 and M2 paradigm of macrophage activation: time for reassessment. F1000prime Rep. (2014) 6:13. doi: 10.12703/p6-13

4. Lichtnekert J, Kawakami T, Parks WC, Duffield JS. Changes in macrophage phenotype as the immune response evolves. Curr Opin Pharmacol. (2013) 13:555-64. doi: 10.1016/j.coph.2013.05.013

5. Wang N, Liang $\mathrm{H}$, Zen K. Molecular mechanisms that influence the macrophage m1-m2 polarization balance. Front Immunol. (2014) 5:614. doi: 10.3389/fimmu.2014.00614

6. Tugal D, Liao X, Jain MK. Transcriptional control of macrophage polarization. Arterioscler Thromb Vasc Biol. (2013) 33:1135-44. doi: 10.1161/ATVBAHA.113.301453

7. Date D, Das R, Narla G, Simon DI, Jain MK, Mahabeleshwar GH. Kruppel-like transcription factor 6 regulates inflammatory macrophage polarization. J Biol Chem. (2014) 289:10318-29. doi: 10.1074/jbc.M113.526749

8. Ganta VC, Choi MH, Kutateladze A, Fox TE, Farber CR, Annex BH. A MicroRNA93-interferon regulatory factor-9-immunoresponsive gene1-itaconic acid pathway modulates M2-Like macrophage polarization to revascularize ischemic muscle. Circulation. (2017) 135:2403-25. doi: 10.1161/CIRCULATIONAHA.116.025490

9. Banerjee S, Xie N, Cui H, Tan Z, Yang S, Icyuz M, et al. MicroRNA let-7c regulates macrophage polarization. J Immunol. (2013) 190:6542-9. doi: 10.4049/jimmunol.1202496

10. Lawrence T, Natoli G. Transcriptional regulation of macrophage polarization: enabling diversity with identity. Nat Rev Immunol. (2011) 11:750-61. doi: $10.1038 /$ nri3088

11. Satoh T, Takeuchi O, Vandenbon A, Yasuda K, Tanaka Y, Kumagai Y, et al. The Jmjd3-Irf4 axis regulates M2 macrophage polarization and host responses against helminth infection. Nat Immunol. (2010) 11:936-44. doi: 10.1038/ni.1920

12. Liao X, Sharma N, Kapadia F, Zhou G, Lu Y, Hong H, et al. Kruppel-like factor 4 regulates macrophage polarization. J Clin Invest. (2011) 121:2736-49. doi: $10.1172 /$ jci45444

13. Odegaard JI, Ricardo-Gonzalez RR, Goforth MH, Morel CR, Subramanian V, Mukundan L, et al. Macrophage-specific PPARgamma controls alternative activation and improves insulin resistance. Nature. (2007) 447:1116-20. doi: 10.1038/nature05894

14. Yang MJ, Song L, Wang L, Yukht A, Ruther H, Li FQ, et al. Deficiency of GATA3-positive macrophages improves cardiac function following myocardial infarction or pressure overload hypertrophy. J Am Coll Cardiol. (2018) 72:885-904. doi: 10.1016/j.jacc.2018.05.061

15. Kraakman MJ, Murphy AJ, Jandeleit-Dahm K, Kammoun HL. Macrophage polarization in obesity and type 2 diabetes: weighing down our understanding of macrophage function? Front Immunol. (2014) 5:470. doi: 10.3389/fimmu.2014.00470

16. Martinez FO, Helming L, Gordon S. Alternative activation of macrophages: an immunologic functional perspective. Annu Rev Immunol. (2009) 27:451-83. doi: 10.1146/annurev.immunol.021908.132532

17. de Pascual-Teresa S, Moreno DA, Garcia-Viguera C. Flavanols and anthocyanins in cardiovascular health: a review of current evidence. Int J Mol Sci. (2010) 11:1679-703. doi: 10.3390/ijms11041679

18. Yang H, Xiao L, Yuan Y, Luo X, Jiang M, Ni J, et al. Procyanidin B2 inhibits NLRP3 inflammasome activation in human vascular endothelial cells. Biochem Pharmacol. (2014) 92:599-606. doi: 10.1016/j.bcp.2014.10.001

19. Chuang CC, McIntosh MK. Potential mechanisms by which polyphenol-rich grapes prevent obesity-mediated inflammation and metabolic diseases. Annu Rev Nutr. (2011) 31:155-76. doi: 10.1146/annurev-nutr-072610-145149

20. Zhou Y, Li Y, Zhou T, Zheng J, Li S, Li HB. Dietary natural products for prevention and treatment of liver cancer. Nutrients. (2016) 8:156. doi: 10.3390/nu8030156
21. Zhang X, Goncalves R, Mosser DM. The isolation and characterization of murine macrophages. Curr Protoc Immunol. (2008) 83: 14.1.1-14. doi: 10.1002/0471142735.im1401s83

22. Wang N, Verna L, Chen NG, Chen J, Li H, Forman BM, et al. Constitutive activation of peroxisome proliferator-activated receptor-gamma suppresses pro-inflammatory adhesion molecules in human vascular endothelial cells. $J$ Biol Chem. (2002) 277:34176-81. doi: 10.1074/jbc.M203436200

23. Bouhlel MA, Derudas B, Rigamonti E, Dievart R, Brozek J, Haulon S, et al. PPAR gamma activation primes human monocytes into alternative M2 macrophages with anti-inflammatory properties. Cell Metab. (2007) 6:137-43. doi: 10.1016/j.cmet.2007.06.010

24. Burns KA, Vanden Heuvel JP. Modulation of PPAR activity via phosphorylation. Biochim Biophys Acta. (2007) 1771:952-60. doi: 10.1016/j.bbalip.2007.04.018

25. Shao D, Rangwala SM, Bailey ST, Krakow SL, Reginato MJ, Lazar MA. Interdomain communication regulating ligand binding by PPAR-gamma. Nature. (1998) 396:377-80. doi: 10.1038/24634

26. Fang L, Zhang M, Li Y, Liu Y, Cui Q, Wang N. PPARgene: a database of experimentally verified and computationally predicted PPAR target genes. PPAR Res. (2016) 2016:6042162. doi: 10.1155/2016/6042162

27. Chalubinski M, Luczak E, Wojdan K, Gorzelak-Pabis P, Broncel M. Innate lymphoid cells type 2 - emerging immune regulators of obesity and atherosclerosis. Immunol Lett. (2016) 179:43-6. doi: 10.1016/j.imlet.2016.09.007

28. Du H, Li L, Bennett D, Guo Y, Turnbull I, Yang L, et al. Fresh fruit consumption in relation to incident diabetes and diabetic vascular complications: a 7-y prospective study of 0.5 million Chinese adults. PLoS Med. (2017) 14:e1002279. doi: 10.1371/journal.pmed.1002279

29. Babu PV, Liu D, Gilbert ER. Recent advances in understanding the antidiabetic actions of dietary flavonoids. J Nutr Biochem. (2013) 24:1777-89. doi: 10.1016/j.jnutbio.2013.06.003

30. Terra X, Montagut G, Bustos M, Llopiz N, Ardevol A, Blade C, et al. Grapeseed procyanidins prevent low-grade inflammation by modulating cytokine expression in rats fed a high-fat diet. J Nutr Biochem. (2009) 20:210-8. doi: 10.1016/j.jnutbio.2008.02.005

31. Byun EB, Sung NY, Byun EH, Song DS, Kim JK, Park JH, et al. The procyanidin trimer C1 inhibits LPS-induced MAPK and NF-kappa B signaling through TLR4 in macrophages. Int Immunopharmacol. (2013) 15:450-6. doi: 10.1016/j.intimp.2012.11.021

32. Baba S, Osakabe N, Natsume M, Terao J. Absorption and urinary excretion of procyanidin B2 [epicatechin-(4beta-8)-epicatechin] in rats. Free Rad Biol Med. (2002) 33:142-8. doi: 10.1016/S0891-5849 (02) 00871-7

33. Stoupi S, Williamson G, Viton F, Barron D, King LJ, Brown JE, et al. In vivo bioavailability, absorption, excretion, and pharmacokinetics of [14C]procyanidin B2 in male rats. Drug Metab Dispos. (2010) 38:287-91. doi: 10.1124/dmd.109.030304

34. Wang L, Yamashita Y, Komeda S, Saito A, Ashida H. Absorption, metabolism, distribution and faecal excretion of B-type procyanidin oligomers in mice after a single oral administration of black soybean seed coat extract. Food Funct. (2018) 9:5362-70. doi: 10.1039/c8fo00852c

35. Holt RR, Lazarus SA, Sullards MC, Zhu QY, Schramm DD, Hammerstone JF, et al. Procyanidin dimer B2 [epicatechin-(4beta-8)-epicatechin] in human plasma after the consumption of a flavanol-rich cocoa. Am J Clin Nutr. (2002) 76:798-804. doi: 10.1093/ajcn/76.4.798

36. Shoji T, Masumoto S, Moriichi N, Akiyama H, Kanda T, Ohtake Y, et al. Apple procyanidin oligomers absorption in rats after oral administration: analysis of procyanidins in plasma using the porter method and high-performance liquid chromatography/tandem mass spectrometry. J Agric Food Chem. (2006) 54:884-92. doi: 10.1021/jf052260b

37. Chen DM, Cai X, Kwik-Uribe CL, Zeng R, Zhu XZ. Inhibitory effects of procyanidin $\mathrm{B}(2)$ dimer on lipid-laden macrophage formation. J Cardiovasc Pharmacol. (2006) 48:54-70. doi: 10.1097/01.fjc.0000242052.60502.21

38. Martinez-Micaelo N, Gonzalez-Abuin N, Terra X, Richart C, Ardevol A, Pinent $\mathrm{M}$, et al. Omega-3 docosahexaenoic acid and procyanidins inhibit cyclo-oxygenase activity and attenuate NF-kappaB activation through a p105/p50 regulatory mechanism in macrophage inflammation. Biochem J. (2012) 441:653-63. doi: 10.1042/BJ20110967 
39. Terra X, Valls J, Vitrac X, Merrillon JM, Arola L, Ardevol A, et al. Grape-seed procyanidins act as antiinflammatory agents in endotoxin-stimulated RAW 264.7 macrophages by inhibiting NFkB signaling pathway. J Agric Food Chem. (2007) 55:4357-65. doi: 10.1021/jf0633185

40. Sakano K, Mizutani M, Murata M, Oikawa S, Hiraku Y, Kawanishi S. Procyanidin B2 has anti- and pro-oxidant effects on metalmediated DNA damage. Free Rad Biol Med. (2005) 39:1041-9. doi: 10.1016/j.freeradbiomed.2005.05.024

41. Ahmadian M, Suh JM, Hah N, Liddle C, Atkins AR, Downes M, et al. PPAR gamma signaling and metabolism: the good, the bad and the future. Nat Med. (2013) 19:557-66. doi: 10.1038/nm.3159

42. Leff T. AMP-activated protein kinase regulates gene expression by direct phosphorylation of nuclear proteins. Biochem Soc Trans. (2003) 31:224-7. doi: 10.1042/bst0310224

43. Akahoshi T, Namai R, Murakami Y, Watanabe M, Matsui T, Nishimura A, et al. Rapid induction of peroxisome proliferator-activated receptor gamma expression in human monocytes by monosodium urate monohydrate crystals. Arthritis Rheum. (2003) 48:231-9. doi: 10.1002/art.10709

44. Wang LM, Waltenberger B, Pferschy-Wenzig EM, Blunder M, Liu X, Malainer C, et al. Natural product agonists of peroxisome proliferatoractivated receptor gamma (PPAR-gamma): a review. Biochem. Pharmacol. (2014) 92:73-89. doi: 10.1016/j.bcp.2014.07.018

45. Castellon X, Bogdanova V. Chronic inflammatory diseases and endothelial dysfunction. Aging Dis. (2016) 7:81-9. doi: 10.14336/AD.2015.0803

46. Feng X, Weng D, Zhou F, Owen YD, Qin H, Zhao J, et al. Activation of PPARgamma by a natural flavonoid modulator, apigenin ameliorates obesity-related inflammation via regulation of macrophage polarization. EBioMedicine. (2016) 9:61-76. doi: 10.1016/j.ebiom.2016.06.017

47. Chen M, Zhang J, Hu F, Liu S, Zhou Z. Metformin affects the features of a human hepatocellular cell line (HepG2) by regulating macrophage polarization in a co-culture microenviroment. Diabetes Metab Res Rev. (2015) 31:781-9. doi: 10.1002/dmrr.2761

48. Zhu Y, Li X, Chen J, Chen T, Shi Z, Lei M, et al. The pentacyclic triterpene Lupeol switches M1 macrophages to M2 and ameliorates experimental inflammatory bowel disease. Int Immunopharmacol. (2016) 30:74-84. doi: 10.1016/j.intimp.2015.11.031

49. Yang X, Xu S, Qian Y, Xiao Q. Resveratrol regulates microglia M1/M2 polarization via PGC-1alpha in conditions of neuroinflammatory injury. Brain Behav Immun. (2017) 64:162-72. doi: 10.1016/j.bbi.2017.03.003

50. Liu X, Li J, Peng X, Lv B, Wang P, Zhao X, et al. Geraniin inhibits LPS-induced THP-1 macrophages switching to M1 phenotype via SOCS1/NF-kappaB pathway. Inflammation. (2016) 39:1421-33. doi: 10.1007/s10753-016-0374-7

51. Yin W, Li B, Li X, Yu F, Cai Q, Zhang Z, et al. Anti-inflammatory effects of grape seed procyanidin B2 on a diabetic pancreas. Food Funct. (2015) 6:3065-71. doi: 10.1039/c5fo00496a

52. Zhang L, Wang Y, Li D, Ho CT, Li J, Wan X. The absorption, distribution, metabolism and excretion of procyanidins. Food Funct. (2016) 7:1273-81. doi: $10.1039 /$ c5fo01244a

Conflict of Interest Statement: The authors declare that the research was conducted in the absence of any commercial or financial relationships that could be construed as a potential conflict of interest.

Copyright (C) 2019 Tian, Yang, Yao, Qian, Liu, Xie, Ma, Nie, Lai, Xiao and Wang. This is an open-access article distributed under the terms of the Creative Commons Attribution License (CC BY). The use, distribution or reproduction in other forums is permitted, provided the original author(s) and the copyright owner(s) are credited and that the original publication in this journal is cited, in accordance with accepted academic practice. No use, distribution or reproduction is permitted which does not comply with these terms. 